\title{
Correlación entre Biopsia Endometrial, Curva de Progesterona y Curva de Temperatura Basal en el Diagnóstico de Fase Lútea Inadecuada.
}

Dres.: Carlos Aníbal Ramos*, Luis Ernesto Pérez**, Germán Isaza***.

\section{INTRODUCC!ON}

El término fase lútea inadecuada indica la producción subnormal de progesterona por parte del cuerpo lúteo, durante la fase secretora del ciclo, resultando en un poco adecuado desarrollo del endometrio para la implantación del huevo fertilizado. Constituye el $3.5 \%$ de las causas de infertilidad y 35\% de los abortos repetidos del primer trimestre. La formación de un cuerpo lúteo funcionalmente adecuado requiere de una fase proliferativa normal $y$ depende

* Residente I Ginecología y Obstetricia.

** Jefe Clínica Infertilidad y Endrocrinología Reproductiva.

*** Especialista de Patología.

Departamentos de Ginecología, Obstetricia y Patología del Hospital Militar Central. Bogotá.

Presentado en el XVI Congreso de Ginecología y Obstetricia en Cali, diciembre 1985. de la capacidad de las células de la granulosa para luteinizarse y secretar progesterona $(2,22)$.

Etiología: Se consideran como factores etiológicos de la fase lútea inadecuada:

1. Problemas de el eje hipotálamohipofisiario (2.4) (la mayoría de los casos).

2. Inadecuada estimulación de las células de la granulosa durante la fase folicular por bajos niveles de FSH.

3. Luteinización inadecuada de las células de la granulosa a causa de pico preovulatorio de LH bajo y de corta duración.

4. Defecto primario en el desarrollo folicular (11).

5. Supresión de la liberación de progesterona por niveles de prolactina elevados (14). 
6. Déficit de receptores endometriales a la progesterona (13).

7. latrogénica: Inducción de la ovulación con clomifen y tratamiento con medroxiprogesterona (20).

Se consideran ciclos con fase lútea inadecuada:

1. Fase Lútea Corta: Duración menor a diez días; incidencia del 5.2\% (16).

2. Fase Lútea de Duración normal, pero con niveles bajos de progesterona (20).

3. Fase Lútea Disarmónica: La duración y los niveles de progesterona son normales, pero la biopsia endometrial revela un retraso mayor de dos días (3).

Se consideran con riesgo de fase lútea inadecuada los pacientes con: (5).

\section{Hiperprolactinemia}

2. Aborto habital

3. Inducción de la ovulación

4. Edad mayor de 35 años

El diagnóstico de fase lútea inadecua. da tradicionalmente se ha venido hacien. do con: Curva de temperatura basal, biopsia endometrial y progesterona plas. mática.

La curva de temperatura basal eleva muy poco en la fase secretora o produce una elevación térmica menor de diez días $(2,16)$.

La biopsia endometrial tomada la última semana del ciclo y siguiendo los criterios de Noyes produce desfase mayor de dos días $(4,7,18,24)$. Una dosificación de progesterona plasmática en los días mesoluteínicos del ciclo serć inferior a $30 \mathrm{ng} / \mathrm{ml}$ o a $30 \mathrm{NN} / \mathrm{L}$ (4,
10). La curva de progesterona estará por debajo de la desviación estándar de una curva de progesterona normal.

\section{PROPOSITO}

Correlacionar curva de temperatura basal (CTB), biopsia endometrial ( $\mathrm{Bx}$ endometrial) y curva de progesterona (CP) como métodos diagnósticos de fase lútea inadecuada (FLI) y determinar la sensibilidad y especificidad de cada uno de ellos.

\section{OBJETIVO}

Determinar el mejor método diagnóstico de $F L I$ entre $B x$ endometrial y CP.

\section{MATERIAL Y METODOS}

Se analizan 18 historias clínicas de pacientes infértiles en quienes se diagnosticó $F L I$ en la consulta de infertilidad del Hospital Militar Central de Bogotá en el período de noviembre de 1980 a noviembre de 1985. De 670 historias clínicas se seleccionaron los 18 casos sospechados clínicamente y corroborados con por lo menos dos de las siguientes pruebas: CTB, Bx endometrialy CP. Los 18 casos respondieron favorablemente a la terapéutica espec ífica, normalizándose la fase lútea y 11 que se embarazaron evolucionaron normalmente hasta el parto.

La CTB fue elaborada por las mismas pacientes en hoja especial y con instrucciones precisas que incluian la toma diaria de temperatura oral en la mañana antes de levantarse. Se consideraron compatibles con FLI las curvas con elevación térmica menor de diez días o con una discreta elevación de la temperatura los últimos 14 días. 
Figura No, 1

\section{CURVA NORMAL DE PROGESTERONA EST ANDARIZADA DE 222 MUESTRAS DE PACIENTES DE LA CONSULTA DE INFERTILIDAD CON PATOLOGIA NO ENDOCRINA}

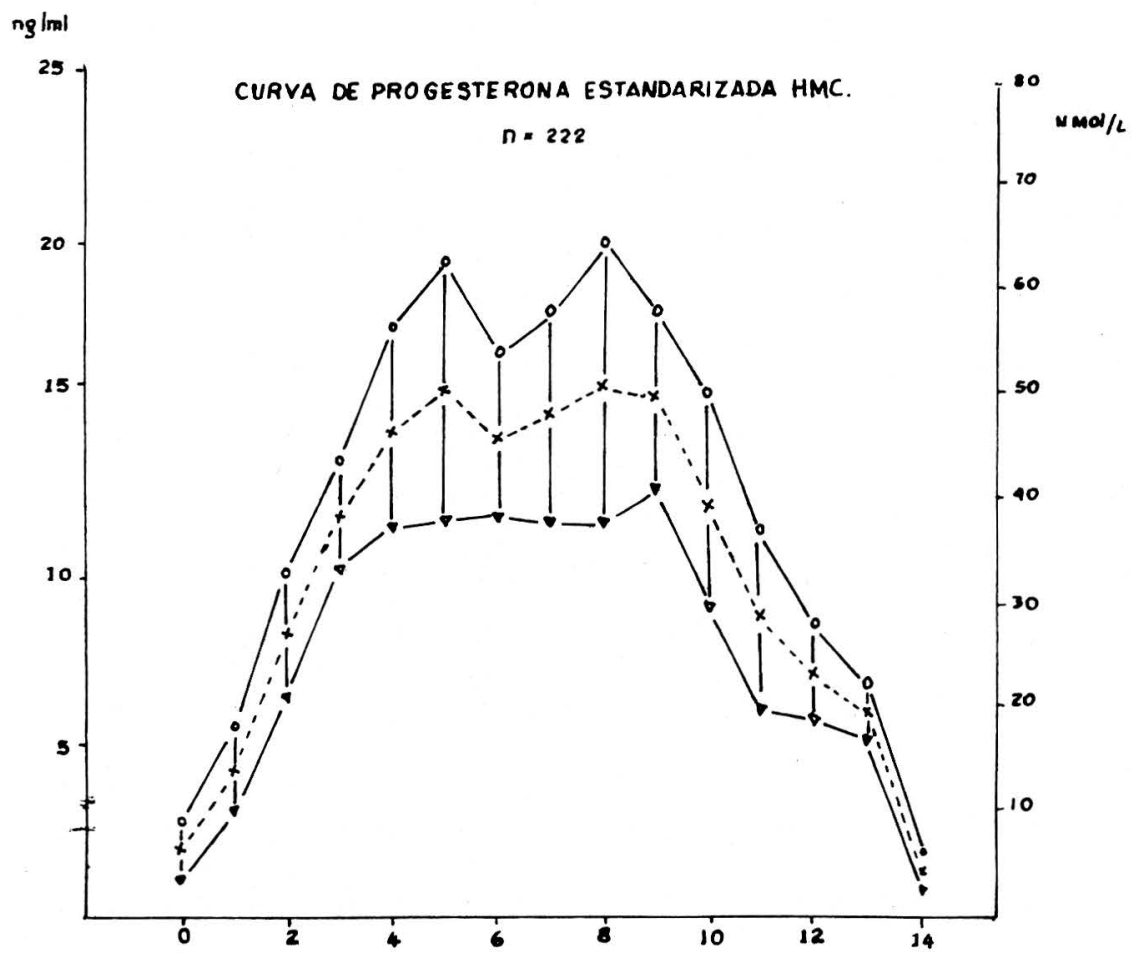

La Bx endometrial se tomó en la última semana del ciclo con curetas de Novak y fue analizada por un sólo patólogo siguiendo los criterios de Noyes $(4,18,24)$. Se consideraron compatibles con FLI las biopsias con desfase mayor de dos días. Para el cálculo de desfase se consideró como día 28 del ciclo el primer día de la menstruación siguiente a la toma de la biopsia. Un año más tarde por método ciego fueron entregadas por el mismo patólogo las placas para una segunda lectura.
La CP consistió en cuantificar por radioinmunoanálisis la progesterona de muestras de sangre tomadas los días, 11 , 7 y 3 premenstruales. La paciente acudia al laboratorio para toma de muestra cada cuatro días a partır del día 16 del ciclo e informaba el inicio de la menstruación siguiente con el objeto de procesar solamente las últimas tres muestras. Los valores obtenidos se analizaron sobre una curva de progesterona elaborada previamente de 222 muestras de proges. terona obtenidas en diferentes días de 
Figura No. 2

\section{CORRELACION ENTRE LOS 3 METODOS DIAGNOSTICO Y RESPUESTA AL TRATAMIENTO.}

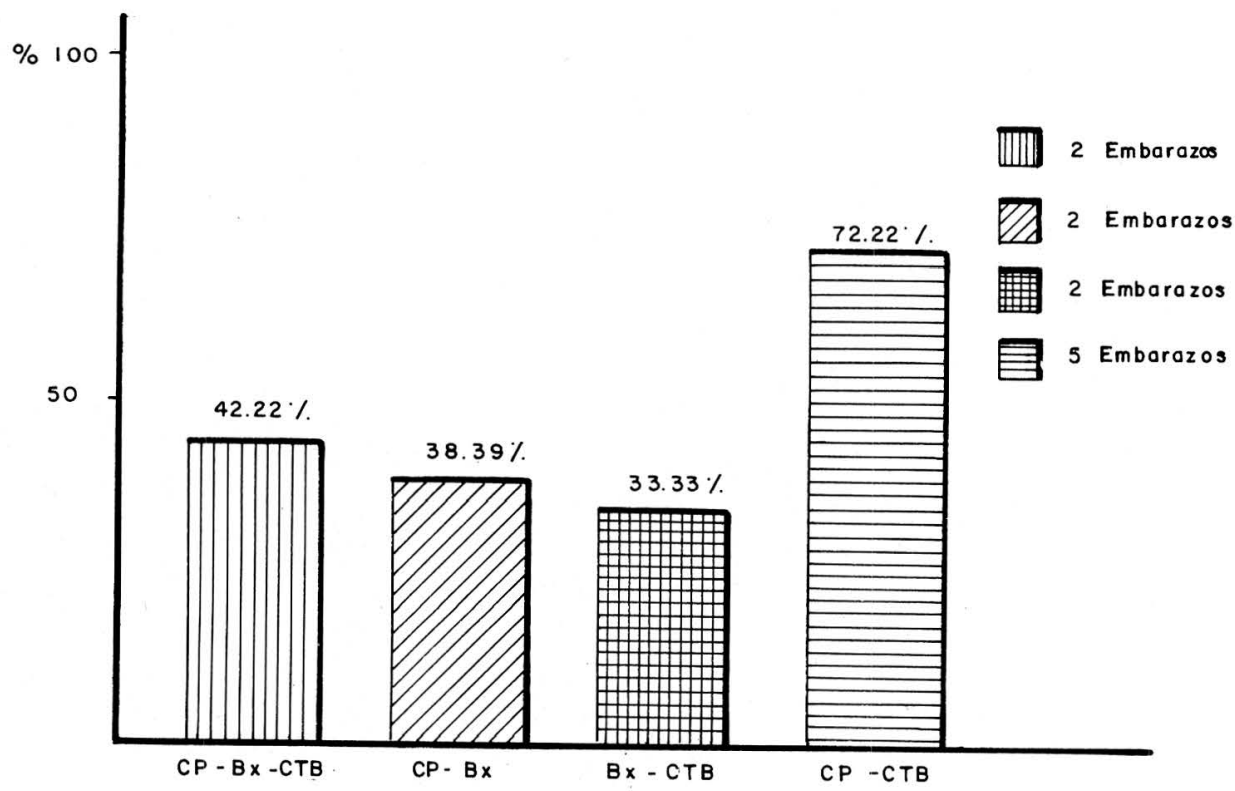

la fase secretora en pacientes con ciclos normales del mismo consultorio de infertilidad cuya infertilidad era causada, por patología no endocrina.

La sensibilidad y especificidad de cada método diagnóstico se determinó tomando la positividad de dos de ellos con respuesta efectiva al tratamiento específico como evidencia de fase lútea inadecuada.

\section{RESULTADOS}

Después de correlacionar 17 de 18 biopsias estaban con desfase los valores individuales de progesterona sérica siempre fueron menores de 30 Nanomoles/
Litro. Los valores promedios tres días, siete días y once días antes de la menstruación fueron de $8,6,15,67$ y 14, 03 Nanomoles por litro respectivamente. (Tabla No. 1).

Se encontró que la curva de progesterona fue más sensible y más específica respecto a la Biopsia Endometrial en el diagnóstico de fase lutea inadecuada. (Figura No. 3).

\section{COMENTARIO}

El diagnóstico de fase lútea inadecuada es difícil ya que hay poca correlación entre las tres pruebas empleadas para 
Tabla No. 1

VALORES DE PROGESTERONA SERICA

( Nm/L) PROMEDIOS EN

PACIENTES CON FLI

\begin{tabular}{crc}
\hline Día del Ciclo & Promedio & Rango \\
\hline$M-1$ & 8.06 & $(3.6-23.12)$ \\
$M-7$ & 15.67 & $(1.0-29.36)$ \\
$M-3$ & 14.03 & $(3.45-27.41)$ \\
\hline
\end{tabular}

Figura No. 3

SENSIBILIDAD Y ESPECIFICIDAD DIAGNOSTICA EN FASE LUTEA

INADECUADA DE CTB, CP Y Bx. ENDOMETRIAL. EN 18 CASOS.

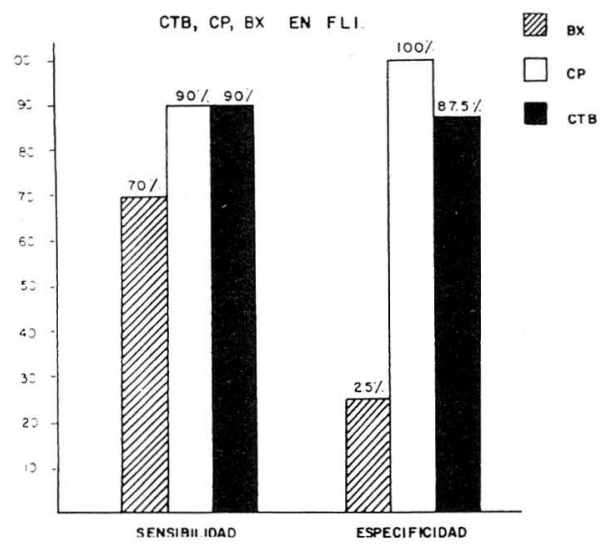

su diagnóstico aún cuando se realizan las tres en el mismo ciclo menstrual.

La CTB muchas veces es difícil de interpretar ya que en buena proporción de los casos las pacientes nuestras a pesar de repetidas explicaciones la elaboran mal.

La biopsia está sujeta a la subjetividad de los patólogos según lo hemos demostrado al hacer leer por método ciego las mismas placas y por el mismo patólogo un año después. Es además, un procedimiento doloroso para ser practicado en el consultorio; no así cuando se realiza simultáneamente con la laparoscopia.

La dosificación sérica de progesterona por radioinmunoanálisis es a nuestro modo de ver mejor para analizar el funcionamiento del cuerpo lúteo y sólo escaparía de su diagnóstico las pacientes con defectos de receptores de progesterona endometriales. Un valor aislado de progesterona mesoluteinica puede hacernos equivocar en el diagnóstico si no lo correlacionamos con la longitud del ciclo estudiado teniendo como día 28 el inicio de la menstruación siguiente. Una curva de progesterona con tres dosificaciones a lo largo de la fase lútea y comparados con una curva estandarizada para la población estudiada pensamos que es la mejor forma de corroborar la sospecha clínica de fase inadecuada.

\section{SUMARIO}

Se analizaron 18 pacientes infertiles en quienes se diagnóstico FLI. A estas mismas pacientes se les solicitó una CTB y una CP sérica, con el objeto de correlacionar estos tres métodos diagnósticos. La $B x$ se tomó en fase secretora y se analizó siguiendo los criterios de Noyes. La progesterona se cuantificó por RIA tomando muestras de sangre en los días 11,7 y 3 premenstruales. La CTB fue tomada por las mismas pacientes en hoja especial. En 7 hubo correlación entre $B x$ y CP. En 6 hubo correlación entre $B x$ y CTB. En 13, correlación entre CP y CTB. Las mismas 18 placas de biopsia endometrial fueron revisadas 1 año más tarde por el mismo patólogo y sólo estuvo de acuerdo con el diagnóstico inicial en 14 casos y en 4 se desfasó más de dos días. De 7 pacientes embarazadas, al hacer tratamiento etiológico hubo más correlación diagnóstico de CTB y la curva de progesterona. El diagnóstico de FLI es difícil por la poca correlación entre Bx y CTB. La CP es la prueba de más valor para el diagnóstico. 


\section{BIBLIOGRAFIA}

1. ABRAHAM G.E., MAROUliS G. G. MARSHALL R: Evaluation of ovulation and corpus luteum function using measurements of plasma progesterone. Obstet Gynecol 44: 522, 1974.

2. ANDREUS WILLIAMS. Defects phase luteal. Fetil Steril 32: 501, 1979.

3. ARCHILLE GRAVENIS, M.S. JEANRENE ZORN: The "Dysharmonic luteal phase" Syndrome endometrial progesterone receptor and estradiol deshidrogenasa. Fertil Steril 42: 730, 1984.

4. BLANSTEIN ANCEL: Pathology of the female genital tract. Second Edition, $287,1983$.

5. COLSTON WENTZ: Consideraciones fisiológicas y clínicas en los defectos de la fase luteinica. COG, (1) 1979.

6. COLSTON WENTZ ANNE: Endometrial biosy in the evaluation of infertility. Fertil Steril 33: 121, 1980.

7. DA-LENSBACH HELLWEG: Histopathology of endometrium. Berlin Springer Verlag, 325, 1975.

8. GRIFF T. ROSS: Maduración luteinica y defecto de la fase luteinica. TAGO. $1978(2)$.

9. HANSLEIGH PA, FAINSTATT: Corpus luteum dysfunction: Serum progesterone levels in diagnosis and assessment of therapy for recurrent and threatened abortion. Fertil Steril 32: 396, 1979.

10. ISRAEL R., MISHELL Dr. STONE SC., et al: Simple luteal phase serum progesterone assay as an indicator of ovulation. Am 3 Obstet Gynecol 112: 1043, 1972.

11. JONES GS: The luteal phase defect. Fertil Steril 127: 351, 1976.
12. JONES GS, ASKELS, WENTZ AC: Serum progesterone values in the luteal phase defects. Obstet Gynecol 44: 26, 1974.

13. KELLER DW, WIEST WG. ASKIN FB, JOHNSON LW, STRICKER RC: Pseudocorpus Luteum Insufficiency: A Local Defect of Progesterone Action on Endometrial Stroma: J. Clin Endocrinol Metab 48: 127, 1979.

14. KANO; T. NISHIKAWA K: Bromocriptine therapy of luteal insufficiency accompanied with hiperprolactinemia in the follicular phase. Nippon Sanka Fujinka Gakkai Zasshi 1983; 35 (7): 975 80.

15. LENTON EA: Normal variation in the lengh of the luteal phase. Br J Obstet Gynecol 1984 Jul;91 (7): 685-9.

16. LENTON EA; LANDGREN BM; SEXTON L: Normal variation in the lengh, of the luteal phase of the menstrual cicle: Identification of the short luteal phase. Ver rẹf. No. 15.

17. MIKHAIL GEORGE. Hormone assays and Gynecologist. Fertil Steril 27, (3), 1976.

18. NOYES RW, HERTIG AT, ROCK J: Dating the endometrial biopsy. Fertil Steril 1: 3, 1950.

19. ROSENFELD DL, GARCIA LR: Endometrial biopsy in the conception. Fertil Steril 26: 1088, 1975.

20. ROSENFELD DL, CHUDOWS, BRONSON RA: Diagnosis of luteal - phase inadequacy. Obstet Gynecol 56: 193, 1980.

21. ROSENFELD DL, GARCIA LR: A Comparison of endometrial histology with simultaneous plasma progesterone determinations in infertile women. Fertil, Steril 27: 1256, 1976. 
22. SEPROFF L: Normal Abnormal menstration. In Current Obstetric Gynecologic Diagnosis and Treatment. 3erd Edition 1980.

23. SHEPARD MK, SENTURIA YD: Comparison of serum progesterone and endometrial biopsy for confirmation of ovulation and evaluation of luteal function. Fertil Steril 28: 541, 1977.
24. WENTZ AC: Endometrial biopsy in the evaluation of infertility. Fertil STERIL 33: 121, 1980.

25. ZORN JR; MC. DONUGH PG. Salivary progesterone as an index of the luteal function. Fertil Steril 1984. 41, (2) 248.

\title{
1986 NATIONAL \& INTERNATIONAL MEETINGS OF OBSTETRICS \& GYNAECOLOGY \& ALLIED SUBJECTS
}

\author{
29 - 31 December 30 th All India Obstetric \& Gynaecological Congress \\ AHMEDABAD (Gujarat) INDIA \\ Contact: Dr. C. B. Purandare \\ Acting Hon. General Secretary F. O.G.S.I. \\ Purandare Griha \\ $31 / \mathrm{C}$ Dr. N. A. Purandare Marg \\ Bombay 400007 - India Tel: 382446
}

\section{NATIONAL \& INTERNATIONAL MEETINGS OF OBSTETRICS \& GYNAECOLOGY \& ALLIED SUBJECTS}

\author{
27 - 30 September VIIIth Congress of ESCO (European Sterility Congress \\ Organization) \\ BUDAPEST-HUNGARY \\ Contact: \\ Scientific matters: Prof. Dr. R. Gimes \\ H 1088 Budapest \\ Baross u. 27 \\ Congress organization: Congress Bureau MOTESZ/8 ESCO \\ H 1361 Budapest \\ P O Box 32
}

